\title{
Evaluating Pre-service Teachers Math Teaching Experience from Different Perspectives
}

\author{
Jenni L. Harding ${ }^{1, *}$, Ilham Hbaci \\ ${ }^{1}$ School of Teacher Education, University of Northern Colorado, USA \\ ${ }^{2}$ Educational Technology, University of Northern Colorado, USA
}

Copyright (C) 2015 by authors, all rights reserved. Authors agree that this article remains permanently open access under the terms of the Creative Commons Attribution License 4.0 International License.

\begin{abstract}
Are pre-service teachers able to notice their strengths and challenges in teaching? This article reports on a study of pre-service teachers' teaching performance being simultaneously evaluated by themselves and their professor. Thirty-two pre-service teachers created and planned mathematics lessons approved by their professor to be taught in elementary classrooms. The teaching experience of those teachers was videotaped and evaluated by the professor using the Field Assessment Observation Form in the areas of content knowledge, instruction, assessment, classroom management, and affective skills. Furthermore, the pre-service teachers completed a Self-Reflection answering their professors' questions regarding their teaching experience. Mixed methods research analyzed the data. The findings of the quantitative data indicate pre-service teachers evaluated themselves higher than what their professor did in assessment and time management. Moreover, the findings of the qualitative data indicated there were similarities in student engagement, inquiry teaching, and scaffolding identified through the teaching performance between pre-service teachers and their professor.
\end{abstract}

Keywords Pre-Service Teachers, Mathematics, Classroom Management, Elementary, Assessment, Scaffolding Instruction, Inquiry Teaching, Students' Engagement, Professor

\section{Introduction}

Teacher educators are in demand to provide pre-service teachers cohesive courses and guiding principles enabling those teachers to apply what they have learned in university based-course work to the field-based portion of their future profession [36]. However, many studies have concluded pre-service teachers reveal concerns applying theories into actual teaching [4]. This transition from being students who were supported by cooperative teachers and/or university supervisors to new teachers who are fully responsible for learning process and managing classrooms stresses pre-service teachers [33].

Pre-service teachers concerns vary in themes from one study to another; however, pre-service teachers are preoccupied with applying theories in their actual teaching. Because their image of themselves as students does not change once they get in the field experience [22], this concern transforms to some issues related to time management, classroom management, lesson planning, providing clear instructions, and assessing without using rubrics [20]. Many studies have been conducted in the past few years to examine pre-service teachers teaching barriers $[22,33,29]$. These barriers are directly related to their experience including: behavior management, time management, lack of ability to work with students with different needs, and lack of communication skills [18]. Pre-services teachers' strengths include propensity for inquiry, attention to children, and awareness of school/society relationships [13].

Since our aim was to explore strengths and areas of improvements of pre-service teachers, we reviewed literature that focused on pre-service teachers teaching experience and several of the mentioned barriers and the teaching strengths identified through our research. The following literature review reinforces the themes found through this research: classroom management, assessment, scaffolding, inquiry teaching, and student engagement.

\section{Management}

All management types identified through this research such as classroom management, time management, instructional management, and behavior management play significant roles to establish an educational atmosphere for both teachers and their students. Emmer \& Stough [11] define classroom management as teachers' activities that "order, engage students, or elicit their cooperation" (p. 103), even though some literature defines classroom management and behavior management interchangeably [30]. Shin \& Koh [34] posit a difference between the two. They state student behavior management focuses on modifying students' behavior. Pre-service teachers should be aware of the behavior management strategies to confirm the learning 
process cannot be interrupted by misbehaving students causing other students to lose their chances to learn [34]. Time management is one of the barriers pre-services teachers reveal $[22,4]$. It is crucial because new teachers have to organize their time between teaching, preparing, and reflecting [22]. Teacher educators should impart time management strategies for teaching content allowing pre-service teachers to experience these strategies in actual teaching environments [4].

Shin \& Koh [34] summarized the Attitudes and Beliefs on Classroom Control Inventory and measured instructional management by items including: students transition from one learning activity to another, monitoring students learning behavior, assigning students to specific seats in the classroom, providing feedback regarding students' performance, teachers decision as to what topics and tasks students need to study, teacher allocation of classroom materials and supplies, implementing the structure of students daily routine, providing homework for drill and practice of skills learned at school, setting time for each learning activity, and trying to stay within schedules.

Classroom management is the biggest area of concern for pre-service teachers during field experience. For instance, Beeth and Adnan [4] have conducted a study with forty two pre-service teachers who reflected on their barriers and strengths through field experience. The researchers concluded classroom management was the highest area pre-service teachers expressed as a weakness during their teaching experience.

\section{Assessment}

Assessment is one of pre-service teachers' concerns. Formative assessment is a tool teacher educators use to improve pre-service mathematics teachers' conceptual understanding [21]. Pre-service teachers should be knowledgeable of assessment approaches because it is their instrument to document student content understanding, reflects on their own teaching, and collaboration with others [2]. Self-assessment is an approach to conduct formative assessment and it assists pre-service teachers evaluate their teaching quality and student learning in the classroom specifying their strengths and areas of improvement [1].

Informal assessment is also a formative assessment denoting some techniques not restricted by the instructional time [24] It helps teachers identify the strengths and weakness of students who are not able to prove their understanding in formal/ standard exams without stressing them with grades [24]. Informal assessments include items such as homework, logs or journals, debates, games, brainstorming, teacher observation, and story retelling[24].

How pre-service teachers are able to assess their students' learning is also a concern pre-service teachers struggle with while teaching elementary children. In their study, Beeth and Adnan [4] found pre-service teacher have difficulties in developing assessment items and how to grade their students, but this concern was not as immediate as the management issue.

\section{Scaffolding}

Scaffolding refers to all types of classroom activities supporting student learning [5]. These activities relate scaffolding to the sociocultural theory $[37,38]$ because they occur through the interaction either verbally or using body language between learners and teachers. Scaffolding includes activities such as bridging, reasoning, prediction, collaboration, modeling [26], and simulation where "the learner interacts with objects or characters of realistic situations to achieve a specific goal" [31].

Scaffolding is not considered a challenge from pre-service teachers' point of view. For instance, although Beeth and Adnan [4] study showed pre-service teachers did not count working with IEP students and interaction with all students as an issue in their teaching experience, they reveal cooperative or collaboration is one of the their concerns.

\section{Inquiry Teaching}

Inquiry teaching refers to teachers' ability to assist their student in being equipped with analytical skills so as to grasp what underlies scientific aspects [28]. Through this type of teaching, learners would be able to engage with a scientific question, participate in designing procedures, give priority to evidence, formulate explanations, connect explanations to scientific knowledge, and communicate and justify explanations; furthermore, teachers should have deep and full understanding and knowledge of their discipline concepts, in the National Research Council [as cited in 28].

Although pre-service teachers have propensity for inquiry as strengths, it has been and is still a barrier for many classroom teachers [28]. The study of Beeth and Adnan [24] reveals inquiry teaching was one of the highest concerns of the forty two pre-service teachers in their field experience. Inquiry teaching is a challenge for teachers because it requires the use of discussion or discourse for inquiry learning. Discourse is an essential item of inquiry teaching especially for mathematic since it encourages mathematical thinking. Inquiry learning allows teachers to provide feedback after the learning experience to extend students' ideas and help them connect the concept to their experience ([28].

\section{Student Engagement}

Bloom [3] specified that students can be cognitively engaged when they accept challenges and accomplish more than they require. Pre-service teachers should be prepared to engage in their learning by challenging themselves to learn, interact, and reflect in order to obtain the highest benefit from their university courses [8]. Moreover, to maximize the opportunities of verifying their students are engaged, pre-service teachers have to develop engagement techniques tailored to their students' needs and background [14]. Focusing on classroom activities is the key to make students engaged. For example, pre-service teachers of Beeth and Adnan [24] expressed their students were not engaged and motivated because the activities they created did not match 
their students' interest.

The research literature available examines pre-service teachers concerns about teaching students in the classroom through classroom management, assessment, scaffolding, inquiry teaching, and student engagement. To the best of our knowledge, an important missing portion in the literature is the professor's point of view. This study explores pre-service teachers' perceptions by using reflection writing. They revealed their strengths and areas of improvement during their filed experience for one of their university -based mathematics coursework. Simultaneously, a professor evaluated these teachers performance using observation through videotaped classroom teaching of the pre-service teachers [35]. This comparative study investigates whether there is a difference between the professor and pre-service teachers in terms of what they notice about mathematics instruction to children in order to better prepare pre-service teachers.

\section{Research Questions}

The purpose of this study was to find out pre-service teachers strengths and weaknesses in order to identify how teacher educators can provide additional support and prepare their students with skills that smooth the transition from pre-service to professional teachers in their career. The following research questions were addressed in this study:

1. Is there a difference in evaluation outcomes of pre-service teachers' performance between pre-service teachers' perspective and the professor's perspective?

2. What are strengths and challenges in pre-service teachers mathematics teaching performance of elementary aged children from pre-service teachers' and the professor's perspective?

\section{Materials and Methods}

Thirty-two pre-service teachers taking a mathematics methods course while completing a math practicum in the elementary classroom participated in this research. These undergraduate students were in their junior year of their teacher education program. This was a purposeful sample of pre-service teachers who were taking mathematics methods with Dr. Harding.

This research includes pre-service teachers creating mathematics lesson plans to teach in their elementary classroom preapproved by the professor prior to teaching. Each pre-service teacher videotaped the teaching of this mathematics lesson to children. The two documents analyzed for this research were (1) Field Assessment Observation Form completed by the professor while watching the video evaluating content knowledge, instruction, assessment, classroom management, and affective skills on a $1-5$ scale ( 1 is developing; 2,3 , and 4 are proficient, and 5 is advanced) and (2) Self-Reflection completed by the pre-service teacher answering guided questions provided by the professor including how the lesson went, how mathematical knowledge was furthered, strategies used to monitor student learning, how did mathematical scaffolding of instruction occur, and an overall self-rating of the quality of mathematics teaching to children on a 1-5 scale ( $1=$ no student learning, $2=a$ few students learned, $3=$ half of the class learned, $4=$ most of the class learned, and $5=$ every student in the class learned).

Mixed methods research was used to analyze the data [27]. The qualitative research uses a case study design wherein holistic portrayals of pre-service teachers' mathematics instruction were researched $[9,19,39]$. The analysis was performed at two levels: within each case and across the cases [39]. Steps in qualitative analysis included: (1) preliminary exploration of the data by reading student self-reflections and professor comments of strengths and areas of improvement through memo writing [7]; (2) the coding processes used for first cycle coding were attribute coding and holistic coding; furthermore, the coding process used for the second cycle coding was pattern coding [32], (3) codes were used to develop themes at two levels: within each case and across the cases [39]; and (4) constructing a case study narrative composed of descriptions and themes. The data collection took place from September to November 2013.

The quantitative research uses statistical tool (SPSS \& SAS) to filter and analyze the collected data. Two resources were used to perform this analysis and they are compared to draw our conclusion. The first independent variable was the professor rating pre-service teachers by using the Field Assessment Observation Form on a 1-5 scale and in the areas of content knowledge (literacy content, social studies content, and mathematics content), mathematical instructions, assessment, classroom management, and affective skills. The second independent variable was pre-service teachers rating their performance and experience (Self-Reflection) in the lesson they taught. Their rate was on a 1-5 scale as well. Plotting raw data is depicted in Figure 1 displaying most of the pre-service teachers rated themselves higher than what their professor did.

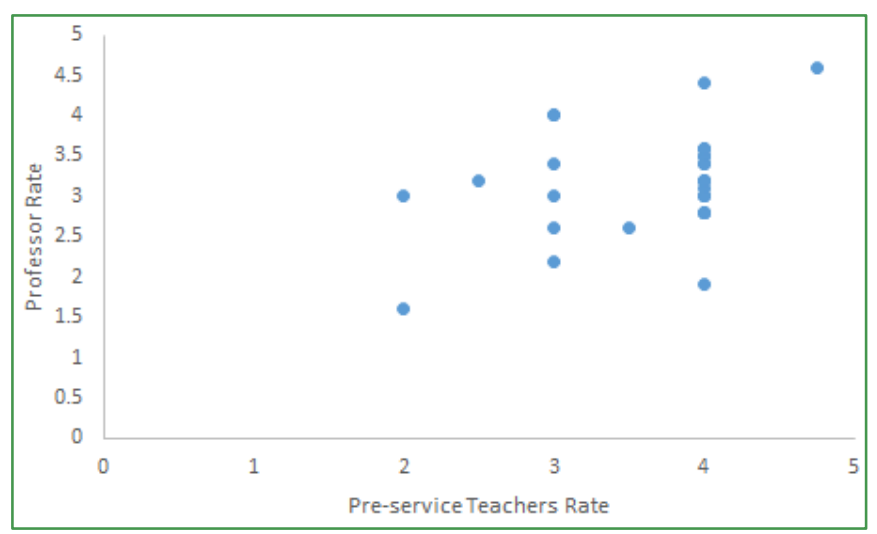

Figure 1. Plotting of Professor Rate and Pre-services Teachers' Rate 


\section{Results}

These mathematics lessons had an average time of 37 minutes (range $=20$ to 90 minutes). There were five qualitative themes revealed in the data: (1) inquiry teaching was effectively implemented into the lessons, (2) children were engaged in learning mathematics, (3) scaffolding of content is a strength, but is lacking when it comes to scaffolding culture, (4) classroom management is identified as the area in need for the largest improvement, and (5) assessment is viewed positively by pre-service teachers, but not observed by the professor. All results are established through the Field Assessment Observation Form completed by the professor and in the pre-service teacher's Self-Reflections.

Seeking to investigate whether the difference between the two teaching observations (professor's rate of pre-services teachers and pre-services teachers rating of themselves) is significant or not, a test of normality has been conducted first to decide the type of the test needed to be used. The analysis showed teacher's rate data is normally distributed, but the pre-services teachers' rate for themselves is not normal. Because of that, Non Parametric Test (Related- Samples Wilcoxon Signed Rank Test) has been used as an alternative for T-Test. The results in Table 1 indicate there is a significant difference between professor rating teachers (mean $\mu=3.1, \mathrm{SD}=0.62, \mathrm{~N}=32$ ) and pre-service teachers rating themselves (mean $\mu=3.6, \mathrm{SD}=0.65, \mathrm{~N}=32$ ) with p-value (0.002) with a level of significance $\alpha=0.05$.

Table 1. Comparison of professor and pre-service Teachers evaluation

\begin{tabular}{|c|c|c|c|c|c|}
\hline Variable & $\mathrm{N}$ & Mean & Minimum & Maximum & Std. Dev \\
\hline Student-Self-Rate & 32 & 3.64 & 2.00 & 4.75 & 0.65 \\
\hline Professor-Rate-Avg & 32 & 3.16 & 1.60 & 4.60 & 0.62 \\
\hline
\end{tabular}

Note: Pre-service teachers' evaluation reported from pre-service Self-Reflection documents (StudentSelfRate variable). TeacherRateAvg variable value obtained from taking the average of the remaining variables the professor valued while observing or watching pre-service teachers' performance (LiteracyCont, SocCont, MathCont, MathInstruction, Assessment, Classroom Management, and Skills. These variables'values are presented in Table2).

Table 2. Values of the Raised Themes From Professor evaluation

\begin{tabular}{|c|c|c|c|c|c|c|}
\hline Theme & $\mathrm{N}$ & Mean & Minimum & Maximum & $\begin{array}{c}\text { Std. } \\
\text { Dev }\end{array}$ & Percent \% \\
\hline $\begin{array}{c}\text { Student } \\
\text { Engagement } \\
\text { (skills) }\end{array}$ & 32 & 3.68 & 1.00 & 5.00 & 0.82 & $73.6 \%$ \\
\hline $\begin{array}{c}\text { Scaffolding } \\
\text { (Math Instruction) }\end{array}$ & 32 & 3.15 & 2.00 & 4.00 & 0.57 & $63 \%$ \\
\hline $\begin{array}{c}\text { Inquiry Teaching } \\
\text { (content) }\end{array}$ & 32 & 3.12 & 2.00 & 5.00 & 0.70 & $62.4 \%$ \\
\hline Assessment & 32 & 3.09 & 2.00 & 5.00 & 0.68 & $61.8 \%$ \\
\hline $\begin{array}{c}\text { Classroom } \\
\text { Management }\end{array}$ & 32 & 2.73 & 0.50 & 5.00 & 0.98 & $54.6 \%$ \\
\hline
\end{tabular}

Note: Content is the average of (literacy content $(\mu=3.33, N=6)$, social studies content $(\mu=3.00, \mathrm{~N}=1)$, and math content $(\mu=3.1, \mathrm{~N}=31))$.

Our data shows that pre-service teacher evaluated their teaching performance $(\mu=3.6)$ higher than their professor $(\mu=3.1)$. As portrayed in Table 2, professor's evaluation of pre-service teachers in the area of assessment has a mean $\mu=3.09(61.8 \%)$, and classroom management has the lowest mean $\mu=2.73(54.6 \%)$. Furthermore, professor's evaluation of pre-service teachers in the area of content (inquiry teaching) has a mean $\mu=3.12(62.4 \%)$, the area of math instruction has a mean $\mu=3.15(63 \%)$, and the area of professional skills has the highest mean $\mu=3.68$ (73\%).

\section{Children Engaged While Learning Mathematics}

These prospective teachers engaged children during mathematics instruction. The professor observed this engagement through math activities, prediction, sentence stems, manipulatives, explicit modeling, involvement with numbers, vocabulary journals, pair/group work with specific student jobs, math games, children's mathematics literature, experiments, opportunities for students to think about problems in multiple ways, students creating their own math problems, and songs/raps about math topics. Engaged children during math learning was confirmed with the students' Self Reflections through the following examples: creating fun activities, students had a good time learning math concepts, student discussions were passionate, students enjoyed the lesson, excited/enthusiastic about math topic, videos, songs/raps, math children's literature, and hands-on activities.

The quantitative data confirms the finding of the qualitative results with mean of $3.68(73.6 \%)$ representing the highest ability of pre-service teachers reported by the professor.

\section{Scaffolding of Mathematics Content}

These pre-service teachers were successful in scaffolding content with children during mathematics instruction. The professor observed this scaffolding through differentiation, guided questions, real life mathematics connections, multiple problems at different math levels, concept maps, creating small groups of students to work with the teacher during independent practice time, multiple entry points as access to math problems, supporting individual students, and sentence stems. Scaffolding content during math learning was confirmed with the students' Self Reflections through the following examples: challenge problems for gifted students, three-column chart, building on background knowledge, vocabulary in multiple languages, different representations of concepts, pictures/visuals/drawings, gestures, think/pair/share, manipulatives, shelter instruction, children's literature, different centers for different students (high, medium, and low math groups), and cooperative learning. However, the scaffolding of culture was an area identified as a weakness. Some of our pre-service teachers showed that they had difficulties when interacting with ESL students, students with learning disabilities, and gifted students.

The quantitative data confirms the finding of the qualitative results with mean of $3.15(63 \%)$ which represents the second highest pre-service teachers' abilities reported by the professor. 


\section{Effective Inquiry teaching}

These pre-service elementary teachers planned and implemented effective inquiry mathematics lessons. The professor observed effective inquiry math learning taking place within the lessons. Some examples of effective inquiry math learning found in the observation data are probability exploration where shapes and double shapes were tossed determining if it lands on its face or side, arrays with coins gaining conceptual understanding of multiplication, measuring objects around the room to find their perimeter, acting out the book to solve mathematical problems, matching written numerals with counter manipulatives, number cards to create larger and smaller numbers, coins connection to decimals, colored sticks pattern creations, measuring centers, and asking higher level questions. Effective inquiry math learning was confirmed with the students' Self Reflections through the following examples: hands-on math activities, explicit vocabulary instruction, effective math strategies used while teaching, guided instruction, manipulative use, asking guiding questions, multiple representations of concepts, building on background and prior knowledge, discovering math, and exploring math concepts.

The quantitative data confirms the finding of the qualitative results with mean of $3.12(62.4 \%)$ representing the third highest pre-service teachers' teaching ability reported by the professor.

\section{Assessment}

These pre-service elementary teachers reflected on assessing students as being one of their strengths with sixteen occurrences of lesson assessments; however, the professor did not observe this abundance of assessments happening through the observations. The pre-service teachers mentioned the following: note taking, thumbs-up/thumbs-down, worksheets, walking around the room, sentence stems, and observation as appropriate assessment taking place during instruction. The professor did not observe any of the pre-service teachers taking notes about formative assessment or using it to clarify or guide the instruction differing from the original lesson plan.

The quantitative data confirms the finding of the qualitative results with mean of 3.09 (61.8\%) representing the second lowest pre-service teachers' abilities reported by the professor.

\section{Classroom Management}

Classroom management is the area needing the largest improvement for these pre-service elementary teachers in terms of behavior management, time management, transitions from one activity to another, and wrapping up the lesson. The professor observed a lack of classroom management through the following examples: back towards the students while teaching, students making distracting noises with papers/materials during directions, materials/manipulatives not ready or organized prior to teaching, lack of time management, lack of classroom control, students not physically close to the pre-service teacher were off task and it was not noticed during instruction, and not having something for students to do when they finish an activity early. A lack of classroom management was confirmed with the students' Self Reflections through the following examples: backs towards students, not sure how to transition from one activity to another, did not have enough materials, students were not listening while giving directions, not knowing how to respond to students, there was too much downtime, calling on all students, and unarticulated expectations. However, pre-service teachers did not mention time management issues. There were eight occurrences observed by the professor including having materials and technology ready, creating seamless transitions, allowing enough time for lesson closure, and using appropriate lesson pacing.

The quantitative data confirms the finding of the qualitative results with mean of $2.73(54.6 \%)$ which represents the lowest pre-service teachers' abilities reported by the professor.

\section{Discussion}

The themes were found from two different perspectives: pre-service teachers themselves and their professor. Qualitative and quantitative data supported the conclusions in the emerged themes. The area of students' engagement, inquiry teaching, and scaffolding (except cultural scaffolding) were evaluated as the highest skills noticed from pre-service teachers themselves and their professor. The classroom management area is evaluated as the highest theme needing the largest improvement from both perspectives as well. The assessment theme is evaluated as a strength from pre-service teachers point of view, but as an area needing to be improved from the professor.

\section{Classroom Management}

We conclude our research is in line with other studies that find pre-service teachers are preoccupied with managing classrooms $[30,34,4]$. The following quotes from pre-service teachers participating in this this study confirm this conclusion:

The biggest issue that I had was how I handled the situation. This was the first time I've worked with such a large group (I usually teach two to ten students at a time), and I did not handle classroom management very well. (Pre-service teacher \#11)

Ineed to work on transitioning from activity to lecture and I need to work on how I close the lesson, the students were finished with the group activity and waiting for me to close the lesson and it could have gone a little smoother. (Pre-service teacher \#10)

Pre-service teachers lacking management skills lead to wasted learning time while attempting to implement several strategies to manage their classrooms instead of teaching 
content [22]. For better preparing pre-service teachers, Borich [6] provides some strategies to assist teachers to be knowledgeable about effective classroom management such as developing a classroom arrangement (how walls are painted, how furniture is aligned, and the board is decorated) that meet the instructional goals. When a classroom is well arranged, communication between students and teacher increases creating students who are motivated to learn. Establishing classroom rules and informing students what behavior is expected from them is also another option. Further, developing routines to assist students with explicit expectations for repeated activities such as group learning experiences. Finally, develop a system as a response to appropriate and inappropriate behavior [6].

\section{Assessment}

Our results indicate pre-service teachers have another area to improve from their professor perspectives: assessment. Pre-service teachers themselves did not reflect on assessment as an area needing to be enhanced. Furthermore, those teachers used formal assessments in terms of worksheets more than informal assessments. The reason might refer to the lack of ability to change their picture as good students to teachers [22]. They were not able to see themselves as teachers who are responsible for all types of assessment to tailor instruction to their students' needs and as something they can use during instruction to guide teaching. Many of the pre-service teachers were focused on management issues, which didn't allow them the time to focus on the assessment of content understanding. The focus was on teaching and managing the students instead of concentrating on what students were learning. When pre-service teachers applied formal assessment methods they learned in university based coursework, they believed they assessed their children successfully; however, what pre-service teachers viewed as successful assessment the professor did not. These pre-service teachers were not able to use informal assessment methods to help guide instruction during teaching because informal assessment needs to be practiced with real interaction with students and these pre-services teachers learned how to assess in their college courses with no children [22]. Furthermore, informal assessment also relates to pre-service subject matter knowledge and this lack of content knowledge might hinder them to answer students' questions [25].

\section{Inquiry Teaching}

Although inquiry teaching is one of classroom teachers obstacles [28], our pre-service teachers demonstrated their ability of applying inquiry teaching into mathematics. Below are some quotes that can be interpreted as strength of inquiry teaching:

I furthered all the students' understanding by asking them questions that caused them to connect to their background "who has a clock at home" "why do we need to tell time". (Pre-service \#8)

I read mathematical story to the entire class and they had to use what they knew about making and understand the different amount of each coin. It helped them also to understand that there are many different ways to create the same amount of change. (Pre-service \#10)

Our interpretation of this successful inquiry teaching refers to some characteristics recognizing pre-service teachers and the active environment they established for teaching. The inquiry teaching was one of the specific items looked for in the lesson plans evaluated by the professor prior to the math teaching in the elementary classroom. Based on what pre-service teachers themselves reflected in addition to their professor observation, their characteristics included "inquiry is in the form of authentic (real-life) problems with the context of the curriculum and/or community data and information are actively used, interpreted, refined, digested and discussed, the teacher models the behaviors of inquirer, the teacher facilitates the process of gathering and presenting information, the teacher and students use technology to advance inquiry (technological items were used such as manipulatives, measuring objects, and cards), and the teacher and students interact more frequently and more actively than during traditional teaching" [17 p.4].

\section{Scaffolding}

Both pre-service teachers and their professor unanimously evaluated the area of scaffolding as one of pre-service teacher's strengths, there is still a gap in the cultural scaffolding. As we mentioned above, pre-service teachers learn teaching methods in an isolated environment different than the real classroom. This might be a reason why pre-service teachers had difficulties in applying cultural scaffolding when they interacted with students. Therefore, they need guides to develop their confidence while they interact with learners in real situations [16] such as providing pre-service teachers with multiple opportunities to teach real classes and increase their connection with students. The following quote from reflective writing supports the claim our pre-service teachers struggled with this part of scaffolding:

The ESL aspect was a little shaky. I made a chart labelling all the parts of division problem in both English and Spanish, I got a little nervous to read each part in Spanish. I would add more ESL aspects in my lessons. (Pre-service \#4)

For this lesson, it was harder to be creative when coming up with a cultural background for students, and relating it to their culture. (Pre-service \#19)

However, I did not include enough differentiation because I did not think of accommodating students with special needs or advanced learners. (Pre-service \#26)

Dar [10] asserted in her study that there is a need to equip pre-service teachers with social skills in their classrooms in order to assist their students having not only academic skills but also effective skills. Both skills will enable pre-service teachers to be good communicators in the community at large. Kea, Campbell-Whatley, Richards [15] confirmed our 
findings regarding pre-service teacher's lack of experience and skills to teach different linguistic and ethical students. Considering the solutions of cultural scaffolding, teacher educators are in demand in preparing pre-service teachers to be culturally responsive agents [15]. Kea and his colleges [15] suggest pre-service teachers should examine and confront negative attitudes that might impact negatively different students learning process. Pre-service teachers also should be prepared to know their students in and out of classrooms [12]. They should be capable to know their students past experience, language, culture, and the like. Furthermore, pre-services teachers should be able to create activities such as direct teaching, large group discussion, small group activities, reading assignments, simulations, and performance activities reflecting care and respecting their students' different culture. Otherwise, the non-included groups will be unintentionally prevented from learning math content [15 p.9].

\section{Engagement}

In terms of students' engagement, our pre-service were able to make their students engaged and the reason of that refer to their ability to establish an active learning environment "something that students do, not something that is done to them" [23 p.2]. In addition, this engagement observed pre-service teachers throughout providing students with a variety of activities that reflect inquiry learning in order to keep them on task and have a focused interaction with the math content.

\section{Conclusions}

The findings of this study demonstrate pre-service teachers during their math teaching performance rate themselves higher than their professor did on the five themes: engagement, scaffolding of instruction, inquiry teaching, assessment, and classroom management. Inquiry teaching and students' engagement were areas of strengths identified through both pre-service teachers and their professor. Scaffolding of instruction was effectively implemented during teaching, but the cultural scaffolding was missing. Assessment was an area positively rated by the pre-service teachers, but not observed by their professor. Classroom management was the area evaluated for improvement from both pre-service teachers and their professor. Classroom management, assessment, and cultural scaffolding continue to be areas where pre-service teachers need additional classroom experiences and practice with children in order to change these challenges into strengths.

\section{REFERENCES}

[1] H. G. Andrade, B. A. Boulay, Role of rubric-referenced self-assessment in learning to write. The Journal of
Educational Research, Vol.97, No.1, 21-30. 2003.

[2] V. L. Akerson, T. A. Cullen, D. L. Hanson, Experienced teachers' strategies for assessing nature of science conceptions in the elementary classroom. Journal of Science Teacher Education, Vol. 21, No.6, 723-745. 2010.

[3] B.S. Bloom, Taxonomy of Educational Objectives: the Classification of Educational Goals, D McKay \& Co, Inc. New York: 1956.

[4] M. E. Beeth, E. Adadan, The influences of university-based coursework on field experience. Journal of Science Teacher Education, Vol 17. No.2, 103-120. 2006.

[5] N. Boblett, Scaffolding: Defining the Metaphor. Teachers College, Columbia University Working Papers in TESOL \& Applied Linguistics, Vol. 12, No.2, 1-16. 2012.

[6] G. D. Borich, Observation Skills For Effective Teaching: Research-Based Practice, Paradigm Publisher, Boulder, CO. 2015.

[7] K. Charmaz, Constructing Grounded Theory: A Practical Guide Through Qualitative Analysis, Sage, Thousand Oaks, CA, 2006.

[8] H. Coates, The value of student engagement for higher education quality assurance. Quality in Higher Education, Vol.11, No.1, 25-36. 2005.

[9] J. W. Creswell, Research design: Qualitative, Quantitative, and Mixed Methods Approaches (3rd ed.), Sage, Los Angeles, 2009.

[10] F. R. Dar, Rethinking Education-Emerging Roles for Teachers. Universal Journal of Educational Research, Vol.3, No.2, 63-74. 2015.

[11] E.T. Emmer, L. M. Stough, Classroom management: a critical part of educational psychology, with implications for teacher education Educational Psychologist, Vol. 36, No.2, 103-112. 2001

[12] J. L. Harding-DeKam, Defining culturally responsive teaching: The case of mathematics. Cogent Education Journal 1(1), DOI 10.1080/2331186X.2014.972676, 2014.

[13] E. V. Howes, Learning to teach science for all in the elementary grades: What do preservice teachers bring? Journal of Research in Science teaching, Vol. 39, No.9, 845-869. 2002.

[14] K. Krause, Understanding and promoting student engagement in university learning communities. Paper presented as keynote address: Engaged, Inert or Otherwise Occupied, 21-22. 2005.

[15] C. Kea, G. D. Campbell-Whatley, H.V. Richards. Becoming culturally responsive educators: Rethinking teacher education pedagogy. Online available from: http://www.nccrest.org/Briefs/Teacher_Ed_Brief.pdf.

[16] A. M. Kagoda, J. Sentongo, Practicing Teachers' Perceptions of Teacher Trainees: Implications for Teacher Education. Universal Journal of Educational Research, Vol.3, No.2, 148-153. 2015.

[17] Minister of Learning. Alberta Learning, Learning and Teaching Resources Branch, Focus on inquiry: a teacher's guide to implementing inquiry-based learning, Learning Resources Centre, Edmonton, Alberta, Canada, 2004. 
[18] D. G. Meister, C. Jenks, Making the transition from preservice to inservice teaching: Beginning teachers' reflections. Action in teacher education, Vol. 22, No.3, 1-11. 2000.

[19] S. B. Merriam, Qualitative Research and Case Study Applications in Education, Jossey-Bass, San Francisco, 1998.

[20] R. Moore. Reexamining the field experiences of preservice teachers. Journal of Teacher Education, Vol.54, No.1, 31-42. 2003.

[21] X. Ma, R. Millman, M. Wells, Infusing assessment into mathematics content courses for pre-service elementary school teachers. Educational Research for Policy and Practice, Vol.7, No.3, 165-181. 2008.

[22] S. A. Melnick, D. G. Meister, A Comparison of Beginning and Experienced Teachers' Concerns. Educational Research Quarterly, Vol. 31, No.3, 39-56. 2008.

[23] National Science Education Standards, National Academy Press, USA, 1996.

[24] C. Navarrete, J. Walide, C.Nelson, R.Martinez, G.Hargett. Informal Assessment in Educational Evaluation: Implications for Bilingual Education Programs. Online available from http://eric.ed.gov/?id=ED337041.

[25] F. Ogan - Bekiroglu, Assessing Assessment: Examination of pre - service physics teachers' attitudes towards assessment and factors affecting their attitudes. International Journal of Science Education, Vol.31, No.1, 1-39. 2009.

[26] J. M. Pentimonti, L. M. Justice, Teachers' use of scaffolding strategies during read alouds in the preschool classroom. Early childhood education journal, Vol.37, No.4, 241-248. 2010.

[27] V. L. Plano Clark, J. Creswell (Eds.), The Mixed Methods Reader, Sage, Thousand Oaks, CA, 2008.

[28] C. Quigley, J. C. Marshall, C. C. M. Deaton, M. P. Cook, M. Padilla, Challenges to Inquiry Teaching and Suggestions for How to Meet Them. Science Educator, Vol.20, No.1, 55-61. 2011.
[29] M. Romano, Successes and struggles of the beginning teacher: Widening the sample. In The Educational Forum, Vol. 72, No. 1, 63-78, 2007.

[30] A. Reupert, S. Woodcock, Success and near misses: Pre-service teachers' use, confidence and success in various classroom management strategies. Teaching and Teacher Education, Vol. 26, No.6, 1261-1268. 2010.

[31] D. Richards, N. Szilas, Challenging reality using techniques from interactive drama to support social simulations in virtual worlds. In Proceedings of The 8th Australasian Conference on Interactive Entertainment: Playing the System, p.12, 2012.

[32] J. Saldana, The Coding Manual for Qualitative Researchers, Sage, Los Angeles, CA, 2009.

[33] M. Schmidt, Mentoring and being mentored: The story of a novice music teacher's success. Teaching and Teacher Education, Vol. 24, No.3, 635-648. 2006.

[34] S. Shin, M. S. Koh, A cross-cultural study of teachers' beliefs and strategies on classroom behavior management in urban American and Korean school systems. Education and Urban Society, Vol. 39, No.2, 286-309. 2007.

[35] J. R. Star, S. K. Strickland, Learning to observe: Using video to improve preservice mathematics teachers' ability to notice. Journal of Mathematics Teacher Education, Vol.11, No.2, 107-125. 2008.

[36] A. Tigchelaar, F. Korthagen, Deepening the exchange of student teaching experiences: implications for the pedagogy of teacher education of recent insights into teacher behaviour. Teaching and teacher Education, Vol. 20, No.7, 665-679, 2004.

[37] L. Vygotsky, Thought and language, Cambridge, MA: MIT Press, 1986.

[38] L. Vygotsky, Mind in society: The development of higher psychological processes, Cambridge, MA: Harvard University Press, 1978.

[39] R. K. Yin, Case Study Research: Design and Methods $\left(4^{\text {th }}\right.$ ed. Vol. 5), Sage, Thousand Oaks, CA, 2009. 